\title{
SYMPOSIUM ON PROCESSES OF GLACIER EROSION AND SEDIMENTATION: OPENING REMARKS
}

\author{
by
}

\author{
L. W. Gold
}

President (1978-1981) of the International Glaciological Society

\begin{abstract}
Great progress has been made during the past 35 years in our knowledge concerning glaciers and glacial processes. The International Glaciological Society has been intimately associated with this progres5, both through its members and its publications. The Journal of Glaciology provides a continuous record of this work for almost 25 years. In it can be traced the topics that have captured the attention of theorists and field glaciologists; the field observations that stimulated the theory builders such as Nye, Weertman, and Liboutry; the theories that resulted; and the progress that occurred when a particular aspect was given a theoretical framework within which it could be considered.

The Society as a whole has periodically summarized and stimulated thought on topical questions concerning glaciers and other large ice bodies through its symposia. The first was on the problems of mass balance that was held as part of the Society's 25th anniversary celebrations in 1962. The proceedings of that meeting are published in Volume 4 of the Journat. The second was in 1969 on the hydrology of glaciers, sponsored jointly with the IASH Commission of Snow and Ice. That symposium was part of the contribution of the Society to the International Hydrologic Decade.

In 1974, the Society held in Cambridge a symposium on remote sensing in glaciology. The proceedings of that meeting provide an excellent summary of the state of knowledge on that subject at that date as well as important information that could only be obtained using remote sensing methods. Its fourth symposium was on
\end{abstract}

the dynamics of large ice masses held in 0ttawa in 1978. That symposium touched on several questions concerning the behaviour of the Arctic and Antarctic ice caps. In 1975 and 1978, the Society also published in the Joumal the proceedings of two symposia with which it was not directly associated. These were the symposium on the thermal regime of glaciers and ice sheets, held in Burnaby, British Columbia, Canada, and the symposium on glacier beds: the ice-rock interface, held in Ottawa at the same time as the Society's meeting.

The present symposium will be the fifth that has been organized by the Society that deals directly with glacier-related topics, and the proceedings will appear in the second volume of our new publication, the Annals of Glaciology. Many of the papers deal with subjects that were considered and debated in earlier meetings. The symposium provides a focus, however, on questions of great past and current interest. What are the erosional processes associated with glaciers, what are the manifestations of these processes, what can we learn concerning past periods of glaciation and climate from these manifestations? The papers indicate the thinking of a broad crosssection of glaciologists and geologists on these questions. Through our discussions both during the sessians and after, we can explore how the new information provided to us affects our knowledge base concerning glaciers and other large ice bodies. I strongly urge you to participate in these discussions to ensure that this symposium will be as successful as earlier ones in providing stimulus for new work and new advances. 
